\title{
Revista de Ciências Agroambientais
}

Engenharia Agrícola

DOI: $10.5327 / \mathrm{Z} 1677-606220192737$

\section{A curva de compactaçáo em Latossolos agrícolas deve ser sempre realizada sem reúso de amostras?}

\author{
Karina de Vares Rossetti ${ }^{1, *}$ (1), José Frederico Centurion ${ }^{2}$ \\ ${ }^{1}$ Universidade do Estado de Mato Grosso, Pontes e Lacerda, MT, Brasil. \\ ${ }^{2}$ Faculdade de Ciências Agrárias e Veterinárias, Universidade Estadual Paulista “Júlio de Mesquita Filho”, Jaboticabal, SP, Brasil. \\ *Autor correspondente: krossetti@bol.com.br
}

Recebido: 10/02/2018; Aceito: 23/10/2018

Resumo: A obtenção da curva de compactação do solo a partir do reúso da amostra altera as suas características, como a textura. É por isso que, na maioria das vezes, recomenda-se o método sem reúso de amostras. Porém, será que se pode generalizar esse fato para todas as classes de solo? Diante dessa dúvida, o presente trabalho teve como objetivo verificar a influência do reúso e do não reúso de amostras de Latossolo Vermelho Distrófico (LVd) e do Latossolo Vermelho Eutroférrico (LVef) sob as curvas de compactação. O delineamento experimental empregado foi o de blocos casualizados em esquema de parcelas subdivididas, com quatro repetições. Os tratamentos (parcelas) foram: $\mathrm{SC}=$ preparo convencional e $\mathrm{MN}$ = mata nativa. As camadas (subparcelas) do solo avaliadas foram as de 0 a 0,10 e de 0,10 a $0,20 \mathrm{~m}$, nas quais foram determinadas a densidade máxima do solo (Dsmáx), a umidade crítica de compactação (Ugc) e a porosidade do solo. A Dsmáx foi superior no LVd em relação ao LVef por causa dos maiores teores de areia em detrimento aos de argila. As operações mecanizadas podem ser realizadas sem degradação física no LVd e LVef, respectivamente na faixa de 0,13 a 0,14 e de 0,23 a $0,25 \mathrm{~kg} \mathrm{~kg}^{-1}$ de conteúdo de água. Com base nos valores de Dsmáx e Ugc, pode-se afirmar que é indiferente a curva de compactação agrícola ser realizada com ou sem reúso de amostras em LVd e LVef.

Palavras-chave: Proctor normal; densidade máxima do solo; umidade crítica de compactação.

\section{Should the compaction curve in agricultural Oxisols always be performed without sample reuse?}

\begin{abstract}
Obtaining the soil compaction curve from the sample reuse changes its characteristics, such as texture. Therefore, the method without sample reuse is most often recommended. But is it possible to generalize this fact to all classes of soil? In view of this doubt, the present work had as objective to verify the influence of the reuse and nonreuse of Haplustox (LVd) and Eutrustox (LVef) samples under the compaction curves. The experiment was conducted in a randomized block design in split-plots and with four replications. The treatments (plots) were: $\mathrm{SC}=$ conventional tillage and $\mathrm{MN}=$ native forest. The soil subplots were $0-0.10$ and $0.10-0.20 \mathrm{~m}$, in which the maximum soil bulk density (Dsmáx), the critical water compaction (Ugc) and the soil porosity were determined. The Dsmáx was higher in the LVd in relation to the LVef because of the sand contents higher than the clay ones. The mechanized operations can be performed without physical degradation in LVd and LVef, respectively in the range of 0.13 to 0.14 and from 0.23 to $0.25 \mathrm{~kg} \mathrm{~kg}^{-1}$ of water content. Based on the values of Dsmáx and Ugc, it can be stated that it is indifferent to the agricultural compaction curve to be performed with and without the reuse of samples in LVd and LVef.
\end{abstract}

Keywords: Proctor test; maximum soil bulk density; critical water content. 


\section{INTRODUÇÁO}

A limitação ao uso do solo pode estar associada à intensificação da agricultura para atender à demanda de crescimento populacional. Nesse sentido, de acordo com a Food and Agriculture Organization (FAO, 2015), aproximadamente 33\% dos solos do mundo estão degradados. Entre os principais problemas estão a erosão, a salinização, a compactação, a acidificação e a contaminação. Em relação à compactação, não só ocorre a redução do volume, como também a alteração da geometria dos poros. Como consequência, os danos causados pela compactação são de longa duração ou mesmo permanentes. Uma compactação que aconteça hoje pode levar à redução da produtividade das culturas até 12 anos mais tarde (FAO, 2015).

Estudos demonstram que, para avaliar a suscetibilidade do solo à compactação, pode-se realizar o ensaio de Proctor Normal, no qual se aplica energia por golpes de um soquete sobre o solo contido em um molde e a massa específica resultante é função do tipo de solo e do conteúdo de água em que o solo estiver. Assim, pode-se determinar a curva de compactação de um solo e estimar o ponto em que se obtém a densidade máxima e a umidade crítica de compactação, na qual ocorre a máxima compactação do solo (ALMEIDA et al., 2014; ROSSETTI \& CENTURION, 2015). De acordo com Klein (2012), tanto a textura como a mineralogia do solo têm influência na densidade máxima do solo (Dsmáx). Luciano et al. (2012), trabalhando com diferentes classes de solos brasileiros, constataram que a Dsmáx aumenta com os teores de areias total e fina e reduz com os de argila.

A elaboração da curva com base no reúso de amostras altera a granulometria original do solo por causa dos impactos da compactação. Segundo Ramos et al. (2013), em Latossolo Vermelho-Amarelo, o reúso de amostras superestima a Dsmáx em menores valores de umidade crítica de compactação (Ugc), por conta da fragmentação de agregados e da reorganização de suas partículas. Porém, esse método apresenta a vantagem de se utilizar uma menor quantidade de solo para a realização do ensaio. Dessa maneira, na maioria das vezes, é recomendado a não utilização de uma única amostra de solo para configurar a curva de compactação. Todavia, será que se pode generalizar esse fato para todas as classes de solo?

Diante dessa hipótese, o presente trabalho teve como objetivo verificar a influência do reúso e do não reúso de amostras de Latossolo Vermelho Distrófico (LVd) e de Latossolo Vermelho Eutroférrico (LVef) sob as curvas de compactação.

\section{MATERIAIS E MÉTODOS}

O ensaio experimental foi realizado em Jaboticabal (SP), localizada próximo às coordenadas geográficas de $21^{\circ} 14^{\prime} 05^{\prime \prime}$ S, 48 $17^{\prime} 09^{\prime}$ W, com altitude de $615 \mathrm{~m}$. O clima da região, de acordo com a classificação climática de Köppen, é do tipo Cwa, com verão quente e inverno seco, precipitação pluvial média anual de $1.428 \mathrm{~mm}$ e temperatura média de $21^{\circ} \mathrm{C}$.

Os solos dos ensaios experimentais foram classificados como LVd, típico, textura média, A moderado, caulinítico-hipoférrico, e LVef, típico, textura argilosa, A moderado, caulinítico-oxídico (EMBRAPA, 2018). No LVd e no LVef cultivados e na mata nativa (MN) no LVd e LVef adjacentes apresentaram-se, respectivamente, na camada de 0 a 0,20 m, 348, 560, 380 e $550 \mathrm{~g} \mathrm{~kg}^{-1}$ de argila, 598, 240, 570 e $180 \mathrm{~g} \mathrm{~kg}^{-1} \mathrm{de}^{-a r e i a, ~ 54, ~ 200, ~ 50 ~ e ~}$ $270 \mathrm{~g} \mathrm{~kg}^{-1}$ de silte e 2,89 (LVd) e 2,74 (LVef) $\mathrm{mg} \mathrm{m}^{-3}$ de densidade de partículas (EMBRAPA, 2017). Os teores de matéria orgânica (MO) para as camadas de 0 a 0,10 e de 0,10 a 0,20 m no LVd e no LVef cultivados e na MN em LVd e LVef foram, respectivamente: 16, 24, 28 e $64 \mathrm{~g} \mathrm{dm}^{-3}$ e 12, 25, 21 e $51 \mathrm{~g} \mathrm{dm}^{-3}$. Na camada de 0 a 0,10 m, os teores dos óxidos de ferro da fração argila $\left(\mathrm{Fe}_{2} \mathrm{O}_{3}\right)$ e da relação da caulinita $(\mathrm{Ct})$ com a gibbsita $(\mathrm{Gb})$ e a relação $[\mathrm{Ct} /(\mathrm{Ct}+\mathrm{Gb})]$ na camada de 0 a $0,10 \mathrm{~m}$ em LVd e LVef foram, respectivamente, 60 e 0,75 e 230 e $0,45 \mathrm{~g} \mathrm{~kg}^{-1}$, segundo dados extraídos de Cunha et al. (2005).

Em novembro do ano agrícola 2013/2014, foi realizado o preparo convencional (SC) do solo a $0,30 \mathrm{~m}$ de profundidade por meio da gradagem de disco média de 18 discos de $660 \mathrm{~mm}$ (26"); foi usada grade leve off-set, modelo ATCR, com sete discos em cada seção (duas), com discos de 0,61 m e distância entre discos de 0,23 m. Estabeleceu-se o tratamento SC com uma área de $21,6 \mathrm{~m}^{2}$ por parcela. Foram utilizadas áreas de MN como tratamento controle por se tratar de uma condição sem ação antrópica. Em cada ensaio, o delineamento experimental foi o de blocos casualizados em esquema de parcelas subdivididas, com quatro repetições. As parcelas foram constituídas pelos tratamentos, e as subparcelas consistiram das camadas de 0 a 0,10 e 0,10 a $0,20 \mathrm{~m}$. Nessas camadas, foram realizados quatro ensaios de Proctor (NOGUEIRA, 1998), com e sem reúso do material coletado para cada tratamento e camada. Na condição de reúso, foram coletados por volta de $5 \mathrm{~kg}$ de solo e. na situação sem reúso, foram coletados $4 \mathrm{~kg}$ de solo para cada ponto da curva de compactação, ou seja, para finalizar cada ensaio de compactação, foram executados seis pontos. 
Todas as amostras foram secas ao ar e passadas em peneira de 4,0 mm. A determinação da Dsmáx consistiu na adição de um pouco de água à amostra (até conseguir moldá-la na mão), seguida pela homogeneização e pela adição de solo até um terço do cilindro de $0,10 \mathrm{~m}$ de diâmetro por $0,13 \mathrm{~m}$ de altura, o qual foi submetido a 25 golpes de um soquete de $2,5 \mathrm{~kg}$, caindo à altura de $0,30 \mathrm{~m}$, correspondendo a uma energia de $560 \mathrm{kPa}$. Posteriormente, adicionou-se mais uma camada de solo até atingir dois terços e depois outra até atingir a superfície do cilindro. Nos pontos seguintes, adicionou-se mais água (cerca de $2 \%$ ), até que se verificou ter a densidade do solo diminuído. Esse procedimento foi realizado para o reúso de amostras e, para a condição sem reúso, as amostras de solo foram disponibilizadas uma em cada bandeja de plástico. Um ponto da curva de compactação correspondeu a uma bandeja, sendo a quantidade de água adicionada aos poucos em ordem crescente para cada bandeja.

Assim, foram obtidas a Dsmáx e a Ugc por meio do ajuste quadrático da equação entre a densidade do solo (Ds) versus a umidade. Para cada amostra, obtiveram-se seis pares de valores de umidade gravimétrica (Ug) e a Ds, com os quais se ajustou a Equação 1:

Ds $=\mathrm{a}+\mathrm{bUgc}+\mathrm{cUg} g^{2}$

Em que:

Ds = densidade do solo $\left(\mathrm{Mg} \mathrm{m}^{-3}\right)$;

$\mathrm{Ug}=$ umidade gravimétrica do solo $\left(\mathrm{kg} \mathrm{kg}^{-1}\right)$;

a, b e c = parâmetros da equação.

Fazendo-se a derivada primeira da Equação 1, foi obtida a umidade crítica para máxima compactação ou Ugc (Equação 2):

$U g c=\frac{-b}{2 a}$

Dessa forma, a Dsmáx pode ser calculada pela Equação 3:

Dsmáx $=\frac{b^{2}-4 a c}{4 a}$

Em que:

Dsmáx $=$ densidade máxima do solo $\left(\mathrm{Mg} \mathrm{m}^{-3}\right)$.

Para avaliar os atributos físicos do solo, em 21 de janeiro de 2013, foram coletadas amostras indeformadas nas camadas de 0 a 0,10 e de 0,10 a $0,20 \mathrm{~m}$, utilizando cilindros de $53,1610^{-6} \mathrm{~m}^{3}(0,032 \mathrm{~m}$ de altura e $0,046 \mathrm{~m}$ de diâmetro), para determinar a Ds, a microporosidade (Micro), que foi determinada por secagem (tensão de -0,006 MPa) em mesa de tensão, e a macroporosidade (Macro), que foi obtida por diferença entre a porosidade total e a Micro (EMBRAPA, 2017).

Os resultados obtidos foram submetidos à análise de variância por meio do software Assistat ${ }^{\circledR}$, versão 7.7 beta, e, quando significativa, as médias foram comparadas pelo teste de Tukey $(p<0,05)$ e, posteriormente, foi realizada a análise de regressão por intermédio do software Microcal Origin ${ }^{\circledR} 8.1$.

\section{RESULTADOS E DISCUSSÃO}

As regressões quadráticas dos ensaios com e sem reúso de amostras foram, em sua maioria, significativas, com exceção da MN sem reúso no LVd na camada de 0 a $0,10 \mathrm{~m}$ e para a camada de 0,10 a $0,20 \mathrm{~m}$ na $\mathrm{MN}$ sem reúso no LVd, no SC sem reúso e na MN sem reúso, ambos no LVef na camada de 0,10 a 0,20 m. Os coeficientes de determinação ( $\left.\mathrm{R}^{2}\right)$ variaram de 0,99 a 0,89 para o LVd e 0,98 a 0,89 para o LVef (Tabela 1).

Observou-se que as curvas de compactação com as diferentes formas de uso das amostras apresentaram pequena diferença para o SC no LVd na camada de 0,10 a 0,20 m e no SC no LVef na camada de 0 a 0,10 m (Figuras 1 e 2). Verificou-se discordância com a afirmação de Ramos et al. (2013) de que o ensaio com reúso de amostras superestimou a Dsmáx e reduziu a Ugc em relação ao uso sem reúso. A Ugc, assim como a Dsmáx apresentaram resultados similares quando se comparam os métodos com e sem reúso para o ensaio de Proctor no LVd e LVef em ambas as camadas. Foi observada exceção para a MN no LVd para a camada de 0 a 0,10 m (Tabela 2). 
Segundo Trindade et al. (2011), o reúso da mesma porção de solo na obtenção dos diversos pontos da curva de compactação pode provocar quebra de partículas, tornando o solo mais fino. Essa quebra justifica o aumento da densidade do solo, visto que partículas menores ocupam melhor os espaços vazios do solo, facilitando a expulsão do ar. O valor superior de Dsmáx para o LVd deve-se ao maior teor de areia nesse solo. Complementa-se que essa justificativa também se infere com a mineralogia, ao maior teor de areia e densidade de partícula $\left(2,89 \mathrm{mg} \mathrm{m}^{-3}\right)$ em comparação ao LVef. A razão Ct / $(\mathrm{Ct}+\mathrm{Gb})$ diminuiu do LVd $(0,75)$ para o LVef $(0,45)$, coincidindo com o aumento dos óxidos de Fe no mesmo sentido (60 e $230 \mathrm{~g} \mathrm{~kg}^{-1} \mathrm{de} \mathrm{Fe}_{2} \mathrm{O}_{3}$ para o LVd e o LVef, respectivamente).

Os maiores teores de MO e de argila do LVef aumentam a adsorção de água pelo solo, comparado ao LVd. Dessa maneira, o LVd compacta-se em menor conteúdo de água em relação ao LVef (Tabela 2). Na MN, também foram obtidos maiores valores de Ugc em comparação ao SC, em razão de o teor de MO ser quase o dobro no LVd e um pouco maior que o dobro no LVef em relação ao solo cultivado. A grande capacidade de retenção de água da MO reduz a quantidade de água entre as partículas minerais do solo, sendo necessário um maior conteúdo de água no solo para diminuir a coesão e o atrito interno entre as partículas e promover sua lubrificação para que ocorra a compactação e a densidade máxima atingida (BRAIDA et al., 2006).

Observaram-se valores inferiores de Dsmáx na MN em relação ao SC independente do método do ensaio de compactação em laboratório. Conforme Braida et al. (2006), os menores valores de Dsmáx na MN ocorrem por conta da elevada quantidade de raízes, folhas e material orgânico em decomposição, o que dificulta a compressão do solo, dissipando a energia de compactação. Neste estudo, as operações mecanizadas podem ser realizadas sem degradação física no LVd e LVef, respectivamente, na faixa de 0,13 a 0,14 e de 0,23 a $0,25 \mathrm{~kg} \mathrm{~kg}^{-1}$ de conteúdo de água. Conforme

Tabela 1. Resultados da análise de regressão quadrática média da densidade do solo em função da umidade para os diferentes tratamentos nas camadas de 0 a 0,10 e 0,10 a $0,20 \mathrm{~m}$.

\begin{tabular}{|c|c|c|c|c|}
\hline Tratamento & Equação & $\mathbf{R}^{2}$ & Fc & $\mathrm{P}>\mathrm{Fc}$ \\
\hline \multicolumn{5}{|l|}{ LVd } \\
\hline \multicolumn{5}{|l|}{0 a $0,10 \mathrm{~m}$} \\
\hline SC sem reúso & $\hat{y}=0,09+25,92 U g-96,18 U^{2}$ & 0,99 & $27,59^{*}$ & 0,03 \\
\hline SC com reúso & $\hat{y}=-0,55+37,68 U g-145,92 U^{2}$ & 0,97 & $20,24^{* *}$ & 0,04 \\
\hline MN sem reúso & $\hat{y}=0,43+14,39 U g-42,24 U g^{2}$ & 0,89 & $9,28^{\mathrm{ns}}$ & 0,09 \\
\hline MN com reúso & $\hat{y}=-0,52+23,27 U g-62,30 U^{2}$ & 0,97 & $33,88^{* *}$ & 0,03 \\
\hline \multicolumn{5}{|l|}{0,10 a $0,20 \mathrm{~m}$} \\
\hline SC sem reúso & $\hat{y}=-0,54+36,36 U g-137,87 U^{2}$ & 0,91 & $135,23^{*}$ & 0,01 \\
\hline SC com reúso & $\hat{y}=-0,56+35,64 U g-129,98 U^{2}$ & 0,97 & $237,02^{*}$ & 0,00 \\
\hline MN sem reúso & $\hat{y}=0,11+19,07 U g-56,85 U g^{2}$ & 0,89 & $17,19^{\text {ns }}$ & 0,05 \\
\hline MN com reúso & $\hat{y}=-0,02+23,50 U g-78,07 U^{2}$ & 0,97 & $52,69^{* *}$ & 0,02 \\
\hline \multicolumn{5}{|l|}{ LVef } \\
\hline \multicolumn{5}{|l|}{0 a $0,10 \mathrm{~m}$} \\
\hline SC sem reúso & $\hat{y}=-1,29+23,97 U g-50,72 U^{2}$ & 0,98 & $37,59^{* *}$ & 0,02 \\
\hline SC com reúso & $\hat{y}=-0,25+14,97 U g-31,20 U^{2}$ & 0,96 & $714,15^{*}$ & 0,00 \\
\hline MN sem reúso & $\hat{y}=-0,20+8,96 U g-13,78 U^{2}$ & 0,90 & $19,03^{* *}$ & 0,04 \\
\hline MN com reúso & $\hat{y}=-0,32+9,20 U g-13,41 U^{2}$ & 0,94 & $55,58^{* *}$ & 0,02 \\
\hline \multicolumn{5}{|l|}{0,10 a $0,20 \mathrm{~m}$} \\
\hline SC sem reúso & $\hat{y}=-3,74+45,92 U g-99,88 U g^{2}$ & 0,91 & $2,60^{\mathrm{ns}}$ & 0,24 \\
\hline SC com reúso & $\hat{y}=-1,23+23,22 U g-47,95 U^{2}$ & 0,93 & $49,37^{* *}$ & 0,02 \\
\hline MN sem reúso & $\hat{y}=-0,40+11,47 U g-18,59 U g^{2}$ & 0,89 & $17,66^{\mathrm{ns}}$ & 0,05 \\
\hline MN com reúso & $\hat{y}=-1,01+17,06 U g-29,79 U^{2}$ & 0,97 & $282,54^{*}$ & 0,00 \\
\hline
\end{tabular}

$\mathrm{R}^{2}$ : coeficiente de determinação; Fc: valor do F calculado; P: probabilidade de se obter um valor de f $\geq \mathrm{Fc}$; LVd: Latossolo Vermelho Distrófico; SC: preparo convencional; MN: mata nativa; $\hat{y}$ : densidade do solo; Ug: umidade; LVef: Latossolo Vermelho Eutroférrico; *significativo a $\mathrm{p}<0,01$ pelo teste $\mathrm{F}$; ${ }^{* *}$ significativo a $\mathrm{p}<0,05$ pelo teste $\mathrm{F}$; ns: não significativo. 
Trindade et al. (2011), quando o valor da Ugc é alto, confere menor capacidade de compactação ou maior intervalo para realização das operações motomecanizadas. No SC, por se tratar da mesma classe de solo, a condição de reúso e não reúso do ensaio de compactação não interferiu nos valores de Ugc, fato esse esperado, já que esta é dependente do teor de argila no solo (KLEIN, 2012).

O LVd apresentou os maiores valores de areia e os menores de argila e MO em comparação ao LVef, resultando em maior valor de Dsmáx e menor Ugc. A posição do ponto máximo da curva de compactação é influenciada pelo teor de argila, pela MO, e estes também influenciam a posição da curva de compactação ao longo do eixo da umidade, enquanto o teor de areia influi na amplitude da curva de compactação. Em relação à argila, esta apresenta maior capacidade de troca catiônica (CTC) e maior área superficial específica do que a areia e interage mais com a água, diminuindo o efeito lubrificante entre as partículas minerais; dessa maneira, em solo mais argiloso, há maior coesão entre as partículas de solo e menor suscetibilidade à compactação do solo em relação ao solo arenoso (BRAIDA et al., 2006). De acordo com esses mesmos autores, há a necessidade de maior conteúdo de água em solo argiloso para que ocorra a compactação e a Dsmáx.

A Ds apresentou a ordem de $\mathrm{MN}_{\mathrm{LVef}}<\mathrm{SC}_{\mathrm{LVef}}<\mathrm{MN}_{\mathrm{LVd}}=\mathrm{SC}_{\mathrm{LVd}}$. Não houve também interação dessa densidade e da Micro dos tratamentos com as camadas de solo (Tabela 3). Pode-se constatar que a Ds no campo está inferior ao valor apresentado para a Dsmáx. Ou seja, com essa quantificação, pode-se afirmar que os tratamentos não atingiram a máxima compactação do solo. A Macro foi superior no $\mathrm{MN}_{\mathrm{LVef}}>\mathrm{SC}_{\mathrm{LVef}}=\mathrm{MN}_{\mathrm{LVd}}>\mathrm{SC}_{\mathrm{LVd}}$, e seus valores foram superiores a $0,10 \mathrm{~m}^{3} \mathrm{~m}^{-3}$, que é o mínimo necessário para as trocas líquidas e gasosas entre o ambiente externo e o solo e
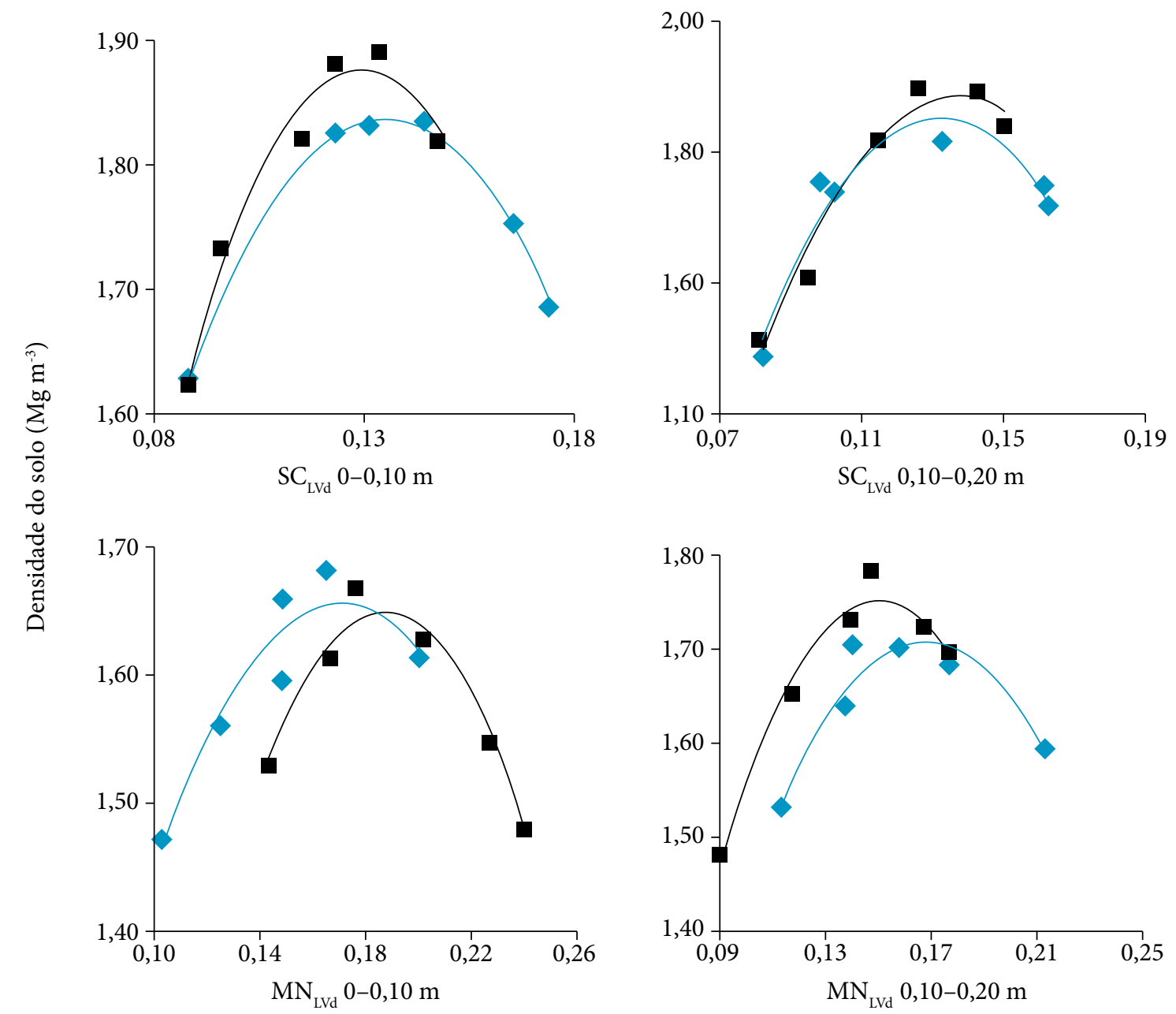

sem reúso

reúso

SC: preparo convencional; LVd: Latossolo Vermelho Distrófico; MN: mata nativa.

Figura 1. Curvas médias de compactação do Latossolo Vermelho Distrófico sob diferentes tratamentos nas camadas de 0 a $0,10 \mathrm{~m}$ e de 0,10 a $0,20 \mathrm{~m}$. 
crítico para o crescimento das raízes da maioria das culturas (REICHERT et al., 2007). O comportamento da Micro seguiu situação inversa ao da Macro.

Pode-se afirmar que não há diferença para a realização do ensaio de compactação com e sem reúso com base nos resultados da Ugc e da Dsmáx. Apenas, como já foi comentado, a Ugc da MN na camada de 0 a $0,10 \mathrm{~m}$ é que revelou uma maior variação para o método do reúso. Por essa razão, ressalta-se a vantagem para a escolha do reúso de amostras por causa da menor necessidade de solo avaliado como no presente estudo para a realização do ensaio. No entanto, é viável ampliar essa avaliação para outras classes de solo, já que, segundo Carvalho (2017), em solos arenosos e com mais pedregulhos a variação de métodos de ensaios é mais significativa provavelmente devido à quebra de grãos na condição de reúso.

\section{CONCLUSÓES}

Em LVd e para o LVef, são indiferentes os valores de DSmáx e de Ugc quando se usa o método sem e com reutilização de amostras. É válido, para as classes de solo do presente estudo, o método de reúso de amostras para caracterizar a curva de compactação do solo para uso agrícola.

\section{AGRADECIMENTOS}

O presente trabalho foi realizado com apoio da Coordenação de Aperfeiçoamento de Pessoal de Nível Superior - Brasil (CAPES), Código de Financiamento 001.
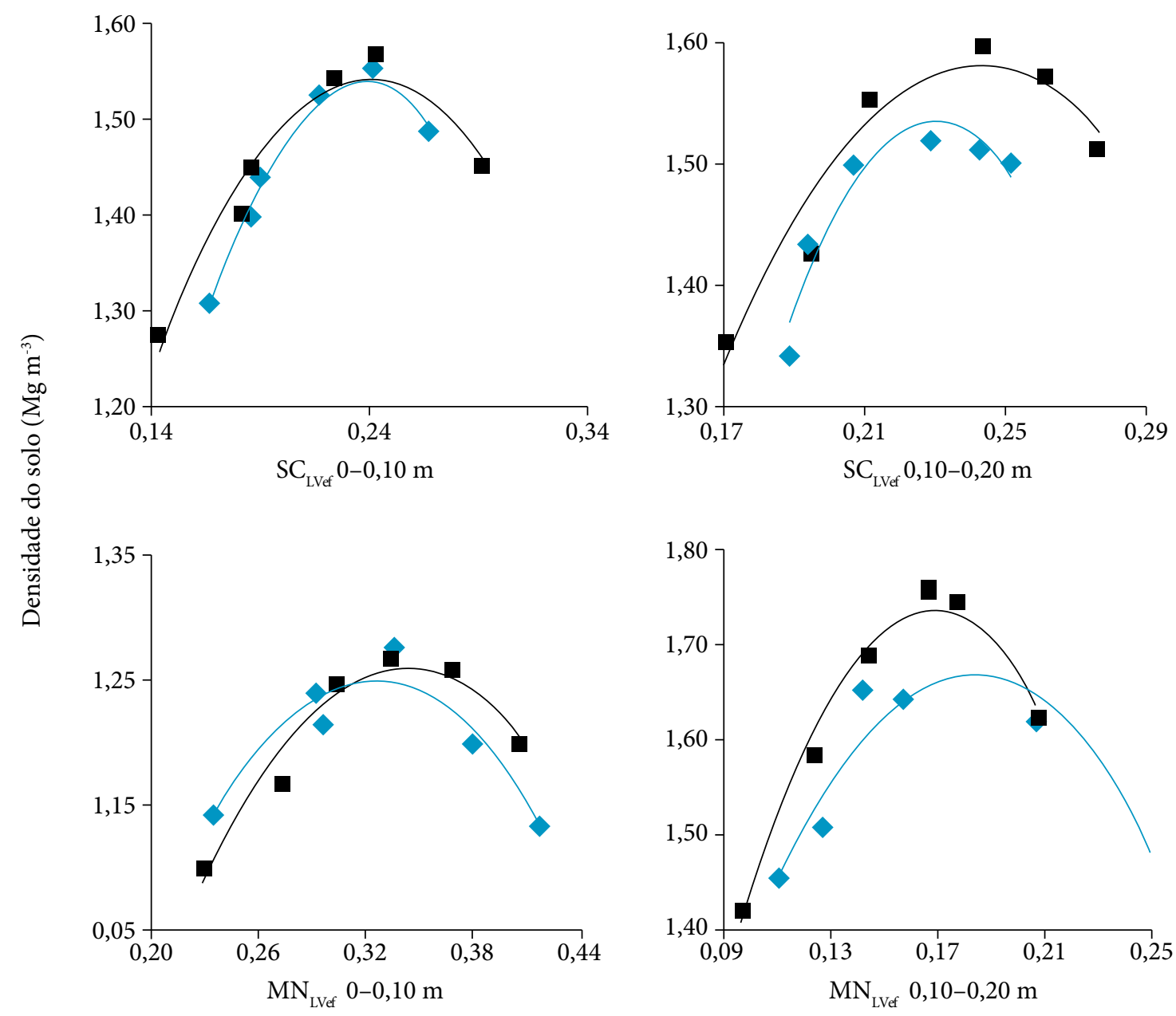

sem reúso

reúso

SC: preparo convencional; LVef: Latossolo Vermelho Eutroférrico; MN: mata nativa.

Figura 2. Curvas médias de compactação do Latossolo Vermelho Eutroférrico sob diferentes tratamentos nas camadas de 0 a $0,10 \mathrm{~m}$ e de 0,10 a $0,20 \mathrm{~m}$. 
Tabela 2. Umidade crítica de compactação e densidade máxima sem e com reúso de amostras em Latossolos sob diferentes tratamentos nas camadas de 0 a 0,10 e 0,10 a $0,20 \mathrm{~m}$.

\begin{tabular}{|c|c|c|c|c|}
\hline \multirow[t]{2}{*}{ Camada (m) } & \multicolumn{2}{|c|}{-------Sem reúso------- } & \multicolumn{2}{|c|}{------Com reúso-------- } \\
\hline & SC & MN & SC & MN \\
\hline \multicolumn{5}{|c|}{$\operatorname{Ugc}\left(\mathbf{k g ~ k g}^{-1}\right)$} \\
\hline \multicolumn{5}{|c|}{ LVd } \\
\hline $0-0,10$ & $0,14 \mathrm{Ea}$ & $0,17 \mathrm{Db}$ & $0,14 \mathrm{Ea}$ & $0,21 \mathrm{Ca}$ \\
\hline $0,10-0,20$ & $0,14 \mathrm{Da}$ & $0,20 \mathrm{BCa}$ & $0,13 \mathrm{Da}$ & $0,18 \mathrm{Cb}$ \\
\hline \multicolumn{5}{|c|}{ LVef } \\
\hline $0-0,10$ & $0,25 \mathrm{Ba}$ & $0,33 \mathrm{Aa}$ & $0,25 \mathrm{Ba}$ & $0,33 \mathrm{Aa}$ \\
\hline $0,10-0,20$ & $0,23 \mathrm{Bb}$ & $0,29 \mathrm{Ab}$ & $0,23 \mathrm{Ba}$ & $0,28 \mathrm{Ab}$ \\
\hline $\mathrm{F}^{1}=112,93^{*}$ & $\mathrm{~F}^{2}=39,42^{*}$ & $F^{1 \times 2}=11,83^{*}$ & $\mathrm{CV}(\%)^{1}=8,25$ & $\mathrm{CV}(\%)^{2}=5,24$ \\
\hline \multicolumn{5}{|c|}{ Dsmáx $\left(\mathrm{Mg} \mathrm{m}^{-3}\right)$} \\
\hline \multicolumn{5}{|c|}{ LVd } \\
\hline $0-0,10$ & $1,85 \mathrm{Aa}$ & $1,52 \mathrm{Bb}$ & $1,88 \mathrm{Aa}$ & $1,55 \mathrm{Bb}$ \\
\hline $0,10-0,20$ & $1,85 \mathrm{Aa}$ & $1,58 \mathrm{Ba}$ & $1,86 \mathrm{Aa}$ & $1,62 \mathrm{Ba}$ \\
\hline \multicolumn{5}{|c|}{ LVef } \\
\hline $0-0,10$ & $1,55 \mathrm{Ba}$ & $1,27 \mathrm{Cb}$ & $1,58 \mathrm{Ba}$ & $1,28 \mathrm{Cb}$ \\
\hline $0,10-0,20$ & $1,55 \mathrm{BCa}$ & $1,42 \mathrm{Da}$ & $1,58 \mathrm{Ba}$ & $1,45 \mathrm{CDa}$ \\
\hline $\mathrm{F}^{1}=55,92^{*}$ & $\mathrm{~F}^{2}=148,90^{*}$ & $\mathrm{~F}^{1 \times 2}=33,57^{*}$ & $\mathrm{CV}(\%)^{1}=4,60$ & $\mathrm{CV}(\%)^{2}=1,12$ \\
\hline
\end{tabular}

SC: preparo convencional; MN: mata nativa; Ugc: unidade crítica de compactação; LVd: Latossolo Vermelho Distrófico; Dsmáx: densidade máxima; LVef: Latossolo Vermelho Eutroférrico; CV: coeficiente de variação; ${ }^{1}$ variação referente aos tratamentos (parcelas); ${ }^{2}$ variação referente às camadas (subparcelas). Médias seguidas de mesma letra não diferem entre si pelo teste de Tukey $(\mathrm{p}<0,05)$. Diferença mínima significativa (DMS) da Ugc 1 : 0,03 e Ugc ${ }^{2}:$ 0,02; DMS da Dsmáx ${ }^{1}: 0,12$ e Dsmáx²: 0,03. Letras maiúsculas referem-se à comparação de tratamentos nas linhas e minúsculas comparam camadas de um mesmo tratamento na coluna; "significativo a $\mathrm{p}<0,01$ pelo teste $\mathrm{F}$.

Tabela 3. Densidade do solo, macroporosidade e microporosidade em Latossolos sob diferentes tratamentos nas camadas de 0 a 0,10 e 0,10 a $0,20 \mathrm{~m}$.

\begin{tabular}{|c|c|c|c|}
\hline Tratamento (A) & Ds $\left(\mathrm{Mg} \mathrm{m}^{-3}\right)$ & $\operatorname{Macro}\left(\mathrm{m}^{3} \mathrm{~m}^{-3}\right)$ & $\operatorname{Micro}\left(\mathbf{m}^{3} \mathbf{m}^{-3}\right)$ \\
\hline $\mathrm{SC}_{\mathrm{LVd}}$ & $1,52 \mathrm{a}$ & $0,212 \mathrm{c}$ & $0,213 \mathrm{~b}$ \\
\hline $\mathrm{MN}_{\mathrm{LVd}}$ & $1,47 \mathrm{a}$ & $0,269 \mathrm{~b}$ & $0,210 \mathrm{~b}$ \\
\hline $\mathrm{SC}_{\text {LVef }}$ & $1,34 \mathrm{~b}$ & $0,319 \mathrm{~b}$ & $0,355 \mathrm{a}$ \\
\hline $\mathrm{MN}_{\text {LVef }}$ & $1,03 \mathrm{c}$ & $0,467 \mathrm{a}$ & $0,253 \mathrm{~b}$ \\
\hline DMS & 0,12 & 0,05 & 0,09 \\
\hline F & $70,58^{*}$ & $75,73^{*}$ & $9,76^{*}$ \\
\hline $\mathrm{CV}(\%)^{1}$ & 5,60 & 11,24 & 23,76 \\
\hline \multicolumn{4}{|c|}{ Camada (B) } \\
\hline $0-0,10 \mathrm{~m}$ & $1,23 \mathrm{~b}$ & $0,340 \mathrm{a}$ & $0,265 \mathrm{a}$ \\
\hline $0,10-0,20 \mathrm{~m}$ & $1,45 \mathrm{a}$ & $0,293 \mathrm{~b}$ & $0,250 \mathrm{a}$ \\
\hline DMS & 0,06 & 0,03 & 0,04 \\
\hline $\mathrm{F}$ & $57,09^{*}$ & $15,59^{*}$ & $0,62^{\text {ns }}$ \\
\hline $\mathrm{F}(\mathrm{A} \times \mathrm{B})$ & $3,33^{\text {ns }}$ & $2,73^{\text {ns }}$ & $0,41^{\mathrm{ns}}$ \\
\hline $\mathrm{CV}(\%)^{2}$ & 6,27 & 10,72 & 20,72 \\
\hline
\end{tabular}

Ds: densidade do solo; Macro: macroporosidade; Micro: microporosidade; SC: preparo convencional; LVd: Latossolo Vermelho Distrófico; MN: mata nativa; LVef: Latossolo Vermelho Eutroférrico; DMS: diferença mínima significativa; ${ }^{1}$ coeficiente de variação referente aos tratamentos (parcelas); ${ }^{2}$ coeficiente de variação referente às camadas (subparcelas). Médias seguidas da mesma letra, no sentido vertical, não diferem entre si pelo teste de Tukey ( $\mathrm{p}<0,05)$; "significativo $(\mathrm{p}<0,01)$; ${ }^{\text {nn }}$ ño significativo. 


\section{REFERÊNCIAS}

ALMEIDA, C.X.; JORGE, R.F.; CENTURION, J.F.; BORGES, E.N.; ROSSETTI, K.V.; PEREIRA, F.S. Qualidade física de um Latossolo Vermelho, sob sistema de semeadura direta e cultivo convencional. Bioscience Journal, Uberlândia, v.30, n.5, p.1395-1411, 2014.

BRAIDA, J.A.; REICHERT, J.M.; VEIGA, M.; REINERT, D.J. Resíduos vegetais na superfície e carbono orgânico do solo e suas relações com a densidade máxima obtida no ensaio de Proctor. Revista Brasileira de Ciência do Solo, Viçosa, v.30, n.4, p.605-614, 2006. http://dx.doi.org/10.1590/S0100-06832006000400001

CARVALHO, M.V. Influência do reúso de amostras no ensaio de compactação de dois Latossolos de Minas Gerais. Viçosa-MG: Universidade Federal de Ouro Preto, 2017. 36f. Monografia (Engenharia Civil), Universidade Federal de Ouro Preto, 2017.

CUNHA, P.; MARQUES JÚNIOR, J.; CURI, N.; PEREIRA, G.T.; LEPSCH, I.F. Superfícies geomórficas e atributos de Latossolos em uma sequência arenítico-basáltica da região de Jaboticabal (SP). Revista Brasileira de Ciência do Solo, Viçosa, v.29, n.1, p.81-90, 2005. http://dx.doi.org/10.1590/S0100-06832005000100009

EMPRESA BRASILEIRA DE PESQUISA AGROPECUÁRIA (EMBRAPA). Centro Nacional de Pesquisas de Solos. Manual de métodos de análises de solo. 3. ed. Rio de Janeiro: Empresa Brasileira de Pesquisa Agropecuária, 2017. 573 p. Disponível em: <https://www.embrapa.br/busca-de-publicacoes/-/publicacao/1085209/manualde-metodos-de-analise-de-solo/>. Acesso em: 5 fev. 2018.

Centro Nacional de Pesquisas de Solos. Sistema brasileiro de classificação de solos. $5^{\text {a }}$ ed. Brasília: Empresa Brasileira de Pesquisa Agropecuária, 2018. 586p.

FOOD AND AGRICULTURE ORGANIZATION (FAO). Status of the world's soil resources. Roma: Intergovernmental Technical Panel on Soils, 2015. 648p. Disponível em: <http:/www.fao.org/publications/>. Acesso em: 15 nov. 2017.

KLEIN, V.A. Física do solo. 2. ed. Passo Fundo: Universidade de Passo Fundo, 2012. 212p.

LUCIANO, R.V.; ALBUQUERQUE, J.A.; COSTA, A.; BATISTELlA, B.; WARMLING, M.T. Atributos físicos relacionados à compactação de solos sob vegetação nativa em região de altitude no sul do Brasil. Revista Brasileira de Ciência do Solo, Viçosa, v.36, n.6, p.1733-1744, 2012. http://dx.doi.org/10.1590/S0100-06832012000600007

NOGUEIRA, J.B. Mecânica dos solos. Ensaios de Laboratório. São Carlos: EESC-USP, 1998. 248p.

RAMOS, F.T.; RAMOS, D.T.; MAIA, J.C.S.; SERAFIM, M.E.; AZEVEDO, E.C.; ROQUE, M.W. Curvas de compactação de um Latossolo Vermelho-Amarelo: com e sem reúso de amostras. Revista Brasileira de Engenharia Agrícola e Ambiental, Campina Grande, v.17, n.2, p.129-137, 2013. http://dx.doi.org/10.1590/S1415-43662013000200003

REICHERT, J.M.; SUZUKI, L.E.A.S.; REINERT, D.J. Compactação do solo em sistemas agropecuários e florestais: identificação, efeitos, limites críticos e mitigação. In: CERETTA, C.A.; SILVA, L.S.; REICHERT, J.M. Tópicos em ciência do solo. 5. ed. Viçosa: Sociedade Brasileira de Ciência do Solo, 2007. p.49-134.

ROSSETTI, K.V.; CENTURION, J.F. Ensaio de compactação em Latossolo cultivado com milho sob diferentes períodos de adoção de tipos de manejo. Revista Brasileira de Ciências Agrárias, Recife, v.10, n.4, p.499-505, 2015. http://dx.doi.org/10.5039/agraria.v10i4a5013

TRINDADE, T.P. da; CARVALHO, C.A.B. de; LIMA, D.C. de; BARBOSA, P.S.A; SILVA, C.H.C; MACHADO, C.C. Compactação dos solos: fundamentos teóricos e práticos. Viçosa: Universidade Federal de Viçosa, 2011. 95p.

Universidade do Estado de Mato Grosso

Campus I - Rod. MT 208, KM 147 - Jardim Tropical - Fone: +55(66) 3521-2041

Revista de Ciências Agroambientais (ISSN 1677-6062) 